\title{
CEAB-INSPIRED RUBRICS FOR ASSESSING DESIGN DOSSIERS IN CAPSTONe Design Courses
}

\author{
Antony J Hodgson and HF Machiel Van der Loos \\ Mechanical Engineering Department, University of British Columbia \\ ahodgson@mech.ubc.ca
}

\begin{abstract}
In the UBC Mechanical Engineering Department, we have recently shifted from using formal reports as our primary documentation process in our capstone design course to a 'design dossier' approach in which students document their work on a task-by-task basis. While this approach has significant benefits in terms of students learning how to document their design work on a routine basis, it has produced challenges in marking a wide range and volume of submissions from different teams working on different projects. In this paper and presentation, we share our experiences of using marking rubrics inspired by the Canadian Engineering Accreditation Board's list of graduate attributes.
\end{abstract}

Keywords: dossier, formal report, capstone, documentation, rubric, CEAB, graduate attributes

\section{INTRODUCTION}

At the 2011 CEEA Meeting, we presented an overview of a new dossier-based documentation process we are using at UBC for our capstone design projects that is intended to be more representative of standard professional practice than the more formal reports we had traditionally used. Our main goal was to increase students' comfort with producing professional documentation as they went and decreasing their sense that documentation processes represent 'busywork' that takes them away from 'real engineering' activities. A key characteristic of these design dossiers was increased flexibility in matching the documentation to the specific requirements of each project, which resulted in a wider variety of submissions than when we required standardized reports. As we deployed this new 13-phase dossier system, the main challenge the instructors encountered in our first year was marking the resulting documentation according to common standards.

In this paper and presentation, we share our experience with a new set of marking rubrics, which we based on the Canadian Engineering Accreditation Board's list of desired graduate attributes.

\section{METHODS}

We began by assigning graduate attributes and subattributes from the CEAB list to each of the thirteen phases of the project in order to focus our attention on what we most wished to assess. For example, in the initial need assessment phase, we concentrated on Attributes 3 and 11 (Investigation; Economics and Project Management) and Sub-Attributes 4.1 and 4.2 (Use of Process; Need and Constraint Identification).

After articulating the relevant attributes associated with each phase, we developed associated rubrics for each phase as a whole, rather than for individual submissions, in keeping with our philosophy that the dossier as a whole should reflect the students' efforts to address the key aspects of each phase of the overall design process.

Each rubric consisted of an attribute or skill we wished to assess, a list of typical artifacts students should consider submitting to show that they had addressed the related design issues, and a set of three descriptors reflecting what we considered to be marginal, competent or exemplary performance with regard to each attribute or skill. For example, the 'competent'-level descriptor for the 'Assessing existing solutions' skill was:

"Most direct competitors identified with evidence of multiple methods used to find competitors. Key performance parameters assessed are linked to conclusions from earlier consultation processes. Parameter estimates are plausible."

We shared the rubrics in advance with the students to focus both their and our attention on the expected level of engagement in the appropriate engineering design activities throughout the course of the project.

\section{RESULTS AND DISCUSSION}

Overall, we were satisfied with the use of these rubrics. Despite the wide variety of submissions across groups, the instructors found it straightforward and quick to assign each group to one of the three competence levels on most rubrics, while providing more specific feedback via written comments on the students' submissions. We expect to add approximately $20 \%$ more rubric elements in the coming year to address attributes and skills that we felt were insufficiently covered in our initial pass. 